UDC 165.742

Grigor ASATRYAN

\title{
CREATIVE POTENTIAL OF HUMANISM
}

\begin{abstract}
The article analyzes the gist and certain specific features of contemporary humanism, reveals its creative and unifying potentials, and sheds light on the role it plays in solving the global problems the humanity faces in the current complicated and critical period of the development of civilization.
\end{abstract}

Keywords: humanism, civilization, creative potential, spiritual unity of the mankind, global problems of today, challenges of the new millennium, antipodes of humanism, confrontation, dehumanization, terrorism.

Humanism as a fundamental worldview concept, a unique and comprehensive teaching, formed back in the Renaissance era, has covered a long and prolific way. One of the key problems of philosophy, it has not only proved viable through the historical evolution, but, having enriched itself with the achievements of the philosophical-theoretical thought and the live practice of the social progress, has deepened its content and acquired unprecedented importance in our days. It is hard to name another philosophic category that would define the distinctive features and the gist of one or another historical epoch so precisely and profoundly, and would assess the progressiveness and social ripeness of one or another society.

Given the new challenges and threats the mankind has been facing lately, the problem of humanism became particularly actual. The historical path of the mankind evidences that in any historical epoch, the human society encountered risks that needed to be neutral- ized for the sake of the further progress of civilization. This tendency has grown into kind of regularity, particularly critical at the current phase of the world history, having no analogues in terms of the extent and gravity of the impending challenges. Menacing are the dimensions of such antipodes of humanism as proliferation of nuclear technologies and militarization of the cosmic space, military conflicts and environmental collisions, increasing negative consequences of the scientific and technological progress, gradual depletion of natural resources, exhaustion of biological resources of the planet Earth, fast and uncontrolled growth of the world population, underproduction of life necessities, developmental lag and poverty in some countries and regions, high level of illiteracy and other negative facts which remain our companions to date. In the modern world, contrary to the logic of historical evolution, political and military collisions, various types of violence, acute socio-economic contradictions, 
national (ethnic) and religious (confessional) intolerance and other prejudices are still to be observed. These risks are of comprehensive, global nature, threaten the entire mankind, its existence per se, which is why the struggle against them acquires increasing actuality, becomes a general problem for all the nations and peoples. To withstand it, people need to consolidate around common goals, unite their material and spiritual potentials.

To overcome the global crisis that fell to the lot of the mankind in the new millennium, new ideas conformable with the ripe problems and inner needs of the epoch, a new model of world perception and assessment of life values should be developed and introduced in the public consciousness to achieve ideologicalpolitical transformation of the contemporary society, to instil humanistic principles of activity, to bring countries and peoples together around common goals, panhuman values and harmonizing interrelations, to create a world without wars and conflicts. Most likely, exactly such prospects of evolution of the humankind had in mind the renowned German philosopher and sociologist Jurgen Habermas when remarking that, if in the XIX-XX centuries, man showed himself as an uncompromising and conflicting being, in the new century he ought to show readiness for accord and compromise.

Among the basic and enduring values, lofty and fundamental ideas, around which the mankind can rally, the ideas of humanism take their deserving place thanks to their significance and life-affirming potential, optimism and mobilizing power, consonance with the vital necessities of the current phase of the evolution of the civilization, with the very spirit of the new epoch.
Humanity has stepped into a radically new, unusual phase of historical development, which most characteristic feature is the unprecedented dynamics of the social progress, deep and radical changes occurring in the world, affecting all the spheres of life, the very basics of human existence. However, these changes and processes are quite contradictory and alarming. The new, technogenic civilization has made the life much more comfortable, yet in no way more humane. The mankind appeared before the lure of hedonism and conformism. Thirst of gain and consumer's psychology root themselves; unrestrained individualism and egoism become dominant, substitute collectivism and altruism.

The modern world, which has become an arena for collisions of confronting sociopolitical and religious-ethnic forces, cannot but disturb and worry. Numerous are the cases of humiliation and disparagement of the interests of small nations and countries. People get estranged from each other, distance themselves from the spiritual values. The cult of violence, brutal force and cruelty is being imposed which, coupled with avidity and thirst of gain, with other negative manifestations that have risen to the top of the scale of values, dissociate people, drain their forces, create an atmosphere of all-round confrontation. Positioned in the center of spiritualmoral reflections, humanism appeared before a fateful alternative, called to determine how much humane a human being will become, how much he will serve his lofty purpose.

The modern progress in science and technologies leads to the formation of a global world. Globalization has become a total, undeniable factor of the world development, relying on the new - informational phase of the 
scientific-technological revolution, which, having penetrated the sphere of information, directly affects the creation, processing, preservation and transmission of information on a global scale.

When the mankind came across the crisis phenomena of the contemporary civilization, the new social realities and challenges of the third millennium, it felt the need for mastering the humanistic legacy of the past, apprehending the classic humanistic values ${ }^{1}$, on the one hand, and, on the other, the need to develop new approaches to the problem of humanism, a new humanistic paradigm, stemming from the specifics of our epoch, from novel socio-historical realities and man-society interrelations, from serious and sizeable problems, and to offer rational ways out of the crisis society, dependable methods and models of solving the ripe problems. This is what we call "rational humanism".

1 The comprehensive problem of humanism we reduce to its three topmost, fundamental aspects. The first of them - the theoretical-philosophical, common worldview aspect, proceeds from the perception of man as the paramount creature of nature, an absolute value, the unique center of the Universe. The second aspect of the problem is a humanistic imperative; it focuses on the creation of such conditions in the world that would ensure an individual's free and unimpeded evolution, full-fledged manifestation of creative aptitudes, physical and spiritual potentials. The third is the ethical aspect of humanism, based on the inculcation of humanistic principles and norms in the interrelations between nations and peoples, all the humans, on the unconditional observance of the principles of humanistic ethics by all the individuals and the world community.
What is the basic content of modern humanism? Which are the fundamental principles and value criteria the new teaching shall be built upon?

The core of the new humanist paradigm is its secular content. It is a scientific materialistic worldview, firmly standing on the pedestal of the thinking mind, reason, relying on the achievements of the modern science, and opposing any manifestation of anti-intellectualism and irrationalism. The strength and viability of modern humanism stem from its scientific nature and rationality ${ }^{2}$. Rationality as a more substantive feature of the new panhuman teaching, acquires a unique and unalterable value. "If we dare again to look for the light of reason', A. Schweitzer writes, 'we will not degrade down to the level of the generation incapable of any enthusiasm, but will burst out with a grand and profound passion of grand and profound ideals" (Schweitzer, 1973 , p. 83). For that reason, the new era of civilization should start with shaping the contemporary humanistic worldview - the "thinking worldview", since "only permanent appealing to the thinking worldview can arouse all the spiritual aptitudes of a human being" (Schweitzer, 1973, p. 82), only through deepening of the thinking worldview is it possible to get out of the dense woods, where we've got lost (Schweitzer, 1973, p. 84). In general, "any real progress in the world is eventually predetermined by rationalism" (Schweitzer, 1973, p. 84).

2 We are convinced that rationality - not in the generally accepted, but in the broad sense of the world - does not only underlie the social reality, the "human's world", but makes an indivisible feature of all existent, of the Universe as a whole. 
An important feature of modern humanism is its panhuman, planetary orientation, for which typical are both dissemination of the fundamental principles of the humanistic worldview at the global developments, and its openness - in certain dimensions - for interaction with diverse philosophical, moral, environmental, political and other doctrines and programs. In this respect, of special value is elaboration of norms of global ethics for the global society. This will give every member of the society an opportunity to rise above the narrow-minded day-to-day interests, moving to the foreground the panhuman interests (see “Humanist Manifesto 2000”, 1999).

Yet another substantial specificity of the new humanist paradigm is the new perception of interrelations between different nations and peoples, cultures and civilizations, the nontraditional approach to their communication and collaboration, the innovative understanding of their role and significance.

The striving for national and cultural seclusion, the nihilistic, negative attitude and, the more so, intolerance to other cultures contradict the spirit of the new time, the evolution of cultures. No culture, for all its uniqueness and value, is self-sufficient and perfect, able to seclude in its shell. Any culture needs to cross own narrow borders, communicate and collaborate with other cultures, and through active communication and collaboration to unveil its hidden creative potentials.

Given this, utterly important are the interrelations between humanism and globalization, the latter being a complex phenomenon with inherent diverse manifestations. As a total phenomenon, void of spiritual-moral senses, it often paves its way as brutal, blind and impersonal social elements with no hu- manistic charge whatsoever, deaf and indifferent to the spiritual constituent of the human life, to the fate of an individual and whole nations and peoples. It is all important not to allow that globalization led to spiritual impoverishment of generations, levelled the specificities of cultures and civilizations, created uniformity, deleted the national (ethnic) and religious (confessional) distinctions, eliminated the linguistic and cultural diversity.

The ideas of humanism are capable of building secure bridges between the dissociating vectors in the social, cultural, ethnic and religious-confessional spheres, thereby contributing to the collaboration of countries and to the well-being of peoples.

Only the life-asserting ideas of humanism, the combined efforts of civilizations and cultures, imbued with the spirit of mutual understanding and solidarity, the sober and viable forces of the modern community are able to withstand the negative manifestations of globalism, its "side effects", to channel the blind and elemental processes of globalization into the fruitful field of the rational. No doubt, it would promote achieving the goals, included in the "Millennium Declaration" (year 2000), which has set guidelines for all the nations to create a more harmonious and better world in the XXI century. In this context, quite valuable and encouraging are the persistent and vigorous efforts of some countries of the former USSR, particularly of the Russian Federation, towards intensification of the integration processes in the Eurasian region, consolidation of the peoples in that region around grand and long-term plans.

One of the cornerstones of the new humanistic teaching is the principle of negation 
and elimination of violence from public life, while the fate of the humanistic ideal is associated with the denial of the ideas of suppression and hegemony. Violence, intolerance and confrontation are unreliable advisers, they cannot lead to truthful and fair decisions. Conflicts are not solved in such ways, but only smoothed down for some time to break out again, still further complicated and exacerbated, fraught with severer and graver consequences.

In such spirit shall advance the struggle between polar and mutually negating ideas. The idea of "new thinking" is taking deeper roots around the world. It relies on the concepts of primacy of panhuman, global values and problems over one-sided, class approaches, the superiority of common civilizational processes over formational ones ${ }^{8}$. These ideas are reflected in the new perception of the global problems, in the interpretation of progress (including scientific-technological) from the perspective of "human dimension", in the acknowledgement of priority of man and humanism, in such notions about the new civilization, where man and man's evolution becomes "an end in itself", "a criterion for everything".

For the global processes happening today, relevant is the analysis of the tendencies of integration from the humanistic standpoint, since they bring about formation of a new community on the bases of humanity and democracy, of a radically new civilization, which over centuries and millennia has been

8 See academician I.T. Frolov's works, particularly, his last interview "The Enigma of Life and the Sacrament of Man: Quests and Delusions", "Voprosy filosofii", 1999, № 8, pp. 3660, (http:/www.frolov-it.ru/interview.html). the dream of the major philosophic trends.

The main mission of the humanistic philosophy is to direct its creative potential towards "exaltation" of man, the interdisciplinary, complex cognition of man applying methodologies of various sciences and arts, having radically changed the priority system in the cultural and social spheres. Not the artificial, mechanical consolidation of different philosophical trends, teachings and schools, not their merger within a "single metasystem", but the common humanistic orientation and pathos, capable of overcoming intolerance and confrontation, will lead to a unique panhuman philosophy, to the formation of "philosophical ecumenism". And, as a result, the deep-laid sacrament of the human existence will become a reality, a spiritual unity of the whole mankind will be created, in which the paramount synthesis of the humanistic philosophy will be achieved.

This humanism is also destined to corroborate the anthropocentric view of the world as a common cradle of human civilization, to instill in the people's minds that, given the differences and peculiarities, caused by worldview, ethnic, religious, cultural and other circumstances of the socio-historical development, they belong to the single human family, bear the same panhuman ideas, values and ideals, are bound together with common goals, common historical fate, that "Gens una sumus", and "Homo homini deus est"10.

Humanism will save the world.

\footnotetext{
9 "We all are one family".

10 "Man to Man is God".
} 


\section{REFERENCE}

Schweitzer, A. (1973). Kul'tura i etika (Culture and Ethics, in Russian.). Moscow: Progress.
Gumanisticheskii manifest 2000. Prizyv k novomu planetarnomu gumanizmu $(\mathrm{Hu}-$ manist Manifesto, 2000. A Call for New Planetary Humanism, in Russian) (1999). Zdravyi smysl, 1, 2-36. 